\title{
Analysis of late-onset neonatal sepsis cases in a level three neonatal intensive care unit
}

\author{
(1) Ali Gul, ${ }^{1}$ () Sahin Takci² \\ ${ }^{1}$ Department of Pediatrics, Gaziosmanpasa University Faculty of Medicine, Tokat, Turkey \\ ${ }^{2}$ Division of Neonatology, Department of Pediatrics, Gaziosmanpasa University Faculty of Medicine, Tokat, Turkey
}

\begin{abstract}
OBJECTIVE: Newborns in neonatal intensive care units (NICUs) are at high risk for developing nosocomial infections (NIs), which may result in morbidity and mortality. In this study, we aimed to ascertain the bacteriological profiles and their antimicrobial susceptibility patterns in NIs.

METHODS: We conducted a cross-sectional study in the NICU. Late-onset sepsis (LOS) cases confirmed with blood cultures were evaluated retrospectively. Laboratory parameters, demographics, and clinical data were collected and analyzed from hospital records retrospectively.

RESULTS: Of the 1210 infants in the NICU, 76 (6.3\%) had LOS. A total of 86 episodes of LOS were documented; in 10 infants, two pathogens were identified. The mean gestational age (GA) of the infants with LOS was $33.2 \pm 4.8$ weeks (23 to 42 weeks). Gram-positive cocci (GPC) caused most of the LOS episodes $(65.8 \%, 50 / 76)$, with coagulase-negative Staphylococcus (CONS) as the most common cause of LOS (50\%, 38/76). Gram-negative rod species (GNRs) accounted for $32.9 \%$ (25/76) of the LOS cases, and fungi accounted for $1.3 \%$ (1/76). The mortality rates for GNR and GPC were $17.9 \%$ and $6.4 \%$, respectively ( $p>0.05$ ). The mean CRP and conjugated bilirubin levels for the GPC and GNR groups were $37.5 \mathrm{vs.} 29.5 \mathrm{mg} /$ $\mathrm{dl}$ and $0.7 \mathrm{vs} 1.5 \mathrm{mg} / \mathrm{dl}$, respectively ( $p>0.05$ ). GNRs had a 20-25\% ceftriaxone resistance. Two (4\%) GPC species were resistant to linezolid, while all were susceptible to vancomycin. All of the GNRs were susceptible to carbapenems.

CONCLUSION: These results underscore the recent emergence of CoNS in NICUs. LOS due to GNRs seems to display higher C-reactive protein and conjugated bilirubin values than those due to GPC. Clinical monitoring of NIs and bacterial resistance profiles are required in all NICUs.
\end{abstract}

Keywords: Antibiotic susceptibility; etiology of neonatal sepsis; newborn; nosocomial infection; sepsis.

Cite this article as: Gul A, Takci S. Analysis of late-onset neonatal sepsis cases in a level three neonatal intensive care unit. North Clin Istanb 2020;7(4):354-358.

A lthough life-saving benefits have been shown for intensive medical care, recent advances may expose critically ill patients to both infectious and noninfectious complications. Neonates represent a unique and highly vulnerable patient population because of their immunologic immaturity and altered cutaneous barriers. Thus, newborns in neonatal intensive care units
(NICUs) are at high risk for developing nosocomial infections (NIs), which results in increased risk for morbidity and mortality [1]. Neonatal risk factors that have been shown to contribute to neonatal sepsis are prematurity, low birth weight, asphyxia, congenital anomalies, exposure to invasive procedures, and prolonged stays in the NICU $[2,3]$.

This study was presented as an oral presentation at the $2^{\text {nd }}$ Congress of the International Neonatology Association in Vienna, Austria, July 15-17, 2016.

Received: December 15, 2018 Accepted: July 01, 2019 Online: May 28, 2020

Correspondence: Ali GUL, MD. Gaziosmanpasa Universitesi Tip Fakultesi, Cocuk Sagligi ve Hastaliklari Anabilim Dali, Tokat, Turkey. Tel: +90 3562129500 e-mail: draligul@yahoo.com

(c) Copyright 2020 by Istanbul Provincial Directorate of Health - Available online at www.northclinist.com 


\begin{tabular}{|lc}
\hline TABLE 1. Microorganisms isolated from blood cultures \\
\hline Microorganism & $\%$ \\
\hline Gram-positive & 65.8 \\
CONS & 50 \\
Staphylococcus aureus & 10.5 \\
Enterococcus spp & 4 \\
Streptococcus pneumoniae & 1.3 \\
Fungus & 1.3 \\
Candida spp & 1.3 \\
Gram-negative & 32.9 \\
Klebsiella spp & 11.8 \\
Escherichia coli & 9.2 \\
Serratia marcescens & 6.6 \\
Enterobacter spp & 4 \\
Pseudomonas aeruginosa & 1.3 \\
\hline
\end{tabular}

CONS: Coagulase-negative staphylococcus.

Despite site-specific infection rates vary by birth weight, NICU NI rates range from $6 \%$ to $25 \%$ [4-6].

Commonly isolated bacterial species from NICUs are Klebsiella pneumonia, Escherichia coli, Enterobacter spp, Pseudomonas aeruginosa, Staphylococcus aureus, Streptococcus spp, Citrobacter spp, and coagulase-negative Staphylococcus (CoNS) [7-9].

Neonatal sepsis may be defined either clinically and/or microbiologically by positive blood and/or cerebrospinal fluid cultures. Also, neonatal sepsis may be classified according to the time of onset of the disease as early-onset sepsis (EOS) and late-onset sepsis (LOS). This distinction has clinical relevance, as EOS is mainly due to bacteria acquired before and during delivery, while LOS is due to bacteria acquired after delivery (from nosocomial or community sources) [9]. In the literature, however, there is little consensus as to what age limits apply. LOS is variably defined as occurring after $72 \mathrm{~h}$ in hospitalized infants to after six days in neonates in the community [10].

The bacterial profiles of blood cultures and the bacterial susceptibility patterns in an area can aid decisions on empirical treatment, which are keys of the management of neonatal sepsis. Thus, in the present study, we aimed to ascertain the bacteriological profiles and antimicrobial susceptibility patterns in NIs. The present study aims to give an overview of the burden of bacterial sepsis in the newborn population and provide an objective basis on which empirical antibiotic therapy should be initiated.

\section{MATERIALS AND METHODS}

We conducted a cross-sectional study from December 01, 2014 until January 31, 2016 in the NICU of the Hospital of Tokat Gaziosmanpasa University Faculty of Medicine, Tokat, Turkey. We defined LOS as a positive blood culture after the first three days of life ( $\geq 72 \mathrm{~h}$ ) [10]. We evaluated the confirmed LOS cases retrospectively. All neonates participated had a thorough clinical evaluation and have processed blood cultures for microbiologic analysis. Each specimen has been inoculated directly into a Bact/ALERT (BioMerieux, Laval, Quebec, Canada) pediatric isolator tube. Antibiotic susceptibility, C-reactive protein (CRP), white blood cell, absolute neutrophil count, immature/total neutrophil ratio, platelet count, mean platelet volume, and biochemical parameters like conjugated and unconjugated bilirubin levels were recorded. Additionally, symptoms, demographics (birth weight, gestational age and sex), duration of hospital stay, and outcome data were collected and analyzed. The only outcome recorded was survival.

Only the first episode of NI was included for analysis, and the detected pathogenic organisms were categorized into three clinically relevant groups as follows: gram-negative rods (GNRs), gram-positive cocci (GPC), and fungi.

\section{Statistical Analysis}

Data were obtained regarding the arithmetic mean, standard deviation, frequency, or percentage. Independent samples t-tests were used to compare the variables between groups. A P-value $<0.05$ was considered statistically significant. Analyses were performed using SPSS 19 (IBM SPSS Statistics 19, SPSS, Somers, NY, USA).

\section{RESULTS}

During the study period, there were 1210 infants in the NICU, and $76(6.3 \%)$ of these infants were noted as having LOS. A total of 86 episodes of LOS were documented; in 10 infants, two pathogens were identified. The mean birth weight of the infants with LOS was $2044 \pm 1031$ grams ( 525 to $4435 \mathrm{~g}$ ). The mean gestational age (GA) of the infants with LOS was $33.2 \pm 4.8$ weeks ( 23 to 42 weeks). The cesarean section ratio for all LOS cases was $67.1 \%$. In the first two weeks of life, $56.6 \%$ of the infants had a central venous catheter.

GPCs were determined to be the cause of most episodes of $\operatorname{LOS}(65.8 \%, 50 / 76)$. GNRs accounted for $32.9 \%(25 / 76)$ of LOS cases, and fungi accounted for 
TABLE2. Laboratory parameters according to LOS groups

\begin{tabular}{lcccc} 
Parameters & $\begin{array}{c}\text { Total } \\
(\mathrm{n}=76)\end{array}$ & $\begin{array}{c}\text { Gram-positive sepsis } \\
(\mathrm{n}=46)\end{array}$ & $\begin{array}{c}\text { Gram-negative sepsis } \\
(\mathrm{n}=30)\end{array}$ & $\mathrm{p}$ \\
\hline WBC $\left(10^{9} / \mathrm{L}\right)$ & $20.6 \pm 17.6$ & $18.3 \pm 2.7$ & $21.9 \pm 16.9$ & 0.48 \\
ANC $\left(10^{9} / \mathrm{L}\right)$ & $5.63 \pm 4.13$ & $5.5 \pm 4.4$ & $5.9 \pm 3.7$ & 0.61 \\
ALC $\left(10^{9} / \mathrm{L}\right)$ & $9.6 \pm 8.2$ & $8.2 \pm 6.1$ & $9.4 \pm 6.1$ & 0.38 \\
I/T ratio & $0.27 \pm 0.06$ & $0.26 \pm 0.06$ & $0.29 \pm 0.05$ & 0.82 \\
CRP $(\mathrm{mg} / \mathrm{dL})$ & $37.5 \pm 48.9$ & $29.5 \pm 33.4$ & $43.2 \pm 54.6$ & 0.23 \\
Hemoglobin $(\mathrm{g} / \mathrm{dL})$ & $15.4 \pm 3.5$ & $15.1 \pm 3.3$ & $15.8 \pm 3.7$ & 0.67 \\
Platelet $\left(10^{9} / \mathrm{L}\right)$ & $211 \pm 129$ & $229 \pm 141$ & $182 \pm 103$ & 0.13 \\
MPV (fL) & $8.8 \pm 1.9$ & $8.7 \pm 2.1$ & $9 \pm 1.6$ & 0.09 \\
Albumin (g/dL) & $3.1 \pm 0.6$ & $3.1 \pm 0.6$ & $3.1 \pm 0.6$ & 0.81 \\
AST (U/L) & $56.8 \pm 52.4$ & $60.3 \pm 52.7$ & $44.9 \pm 41.3$ & 0.11 \\
ALT (U/L) & $18.4 \pm 26.1$ & $18.8 \pm 27.8$ & $7.8 \pm 17.7$ & 0.37 \\
Total bilirubin (mg/dL) & $6.5 \pm 4.3$ & $6 \pm 4.1$ & $1.5 \pm 0.9$ & 0.46 \\
Conjugated bilirubin (mg/dL) & $0.75 \pm 1.26$ & $0.71 \pm 0.5$ & $493 \pm 268$ & 0.06 \\
LDH (U/L) & $560 \pm 300$ & $595 \pm 315$ & $80.4 \pm 26.7$ & 0.26 \\
Glucose (mg/dL) & $84.8 \pm 28.6$ & $86.5 \pm 29.5$ & 0.76 \\
\hline
\end{tabular}

Data are shown as mean \pm standard deviation. Independent samples t-test was used. WBC: White blood cell; ANS: Absolute neutrophil count; ALC: Absolute lymphocyte count; I/T ratio: Immature/total neutrophil ratio; CRP: C-reactive protein; MPV: Mean platelet volume; AST: Aspartate aminotransferase; ALT: Alanine aminotransferase; LDH: Lactate dehydrogenase.

$1.3 \%(1 / 76)$. Table 1 shows the distribution of microorganisms that were isolated from blood cultures. The postnatal age at the time of diagnosis was $16.2 \pm 11.5$ days in the GPC group and $15.4 \pm 10.8$ days in the GNR group ( $p>0.05)$. Central nervous system infection was determined in two cases and urinary tract infection was determined in six cases. Eight of the 76 LOS cases $(10.5 \%)$ died, and the mortality rates for the GNR and GPC groups were $17.9 \%$ and $6.4 \%$, respectively $(\mathrm{p}>0.05)$.

The mean CRP levels were $29.5 \pm 33.4$ and $43.2 \pm 54.6$ $\mathrm{mg} / \mathrm{dl}$ for the GPC and GNR groups, respectively $(p>0.05)$. The mean conjugated bilirubin level was 0.7 $\mathrm{mg} / \mathrm{dl}$ in the GPC group, whereas it was $1.5 \mathrm{mg} / \mathrm{dl}$ in the GNR group, as shown in Table $2(\mathrm{p}>0.05)$.

Skin alterations, such as chilly periphery or cutis marmorata and reduced movement at a rate of $50 \%$, were the most frequent clinical findings. The distribution of the major clinical findings is shown in Table 3.

GNRs showed 20-25\% ceftriaxone resistance. Table 4 shows the selected antibiotic susceptibility of GNRand GPC-positive cases. All were sensitive to carbapenems. Additionally, all GPCs were sensitive to vancomycin. During the study period, vancomycin-resistant enterococcus colonization was present in five infants in the NICU
TABLE 3. Distribution of clinical findings for all subjects

Clinical findings

$\%$

Skin alterations (Pallor or cutis marmorata) 51.3

Hypotonia and Hypoactivity 50

Poor feeding 42.1

Apnea 36.8

Unstable temperature $\quad 30.3$

Respiratory distress $\quad 30.3$

Heart rate variability $\quad 27.6$

GIS findings (distensions, residuals) 27.6

Cyanosis

21.1

GIS: Gastrointestinal system.

who were all transferred to our NICU from other institutions. None progressed to vancomycin-resistant infection.

\section{DISCUSSION}

NIs are a major cause of morbidity in NICUs. NIs are associated with lower birth weight and increased thera- 
TABLE 4. Selected antibiotic susceptibility of gram-negative and gram-positive microorganisms

\begin{tabular}{lc} 
Antibiotic & \multicolumn{2}{c}{ Gram-neg } \\
\cline { 2 - 3 } & Tested isolates \\
\cline { 2 - 3 } & $\mathrm{n}$ \\
\hline Ceftriaxone & 9 \\
Gentamicin & 21 \\
Linezolid & 18 \\
Meropenem & 8 \\
Piperacillin-Tazobactam & 12 \\
Levofloxacin & 14 \\
Cefepime & \\
Ampicillin & \\
Teicoplanin & \\
Vancomycin &
\end{tabular}

\begin{tabular}{ccc}
\multicolumn{3}{c}{ Gram-positive } \\
\hline Tested isolates & \multicolumn{2}{c}{ Susceptible } \\
\cline { 2 - 3 }$n$ & $\mathrm{n}$ & $\%$ \\
9 & 3 & 33 \\
46 & 20 & 43 \\
44 & 96 & \\
& & \\
28 & 18 & 64 \\
28 & & 25 \\
46 & 7 & 98 \\
46 & 45 & 100
\end{tabular}

peutic intensity and result in prolonged hospitalization, leading to increased costs [5]. The increasing number of technology-dependent infants is the primary factor leading to the increase of NIs [11]. Although immunologic immaturity and altered cutaneous barriers play a role in the vulnerability of neonates to NIs, therapeutic interventions that are lifesaving for these fragile infants also appear to be associated with the majority of infectious complications resulting in neonatal morbidity and mortality $[1,2]$.

The prevalence of NIs in NICUs differs among countries and NICUs of the same country. Additionally, seasonal bacteriologic profile changes are likely to occur. Multicenter studies in Europe have reported an overall NICU NI rate of 7\% [12]. Consistent with the present study, in Turkey, the neonatal sepsis frequency ranges from $2.1 \%$ to $17 \%$ in NICUs [7]. Retrospectively evaluation of data-base of 242 neonatal departments has shown the LOS rate in NIs for VLBW infants was $8.1 \%$ with $6.4 \%$ case fatality risk [13].

The pathogens most often implicated in neonatal sepsis in developing countries differ from the pathogens seen in developed countries. However, GNRs are overall more commonly found to cause LOS in resource-limited countries' NICUs [8, 14-17]. Consistent with the present study, various authors have reported that LOS mainly arises from GPCs, especially CoNS $[16,18,19]$. Similar to the present study, the Australasian Study Group for Neonatal Infections reported that CoNS predominated and was responsible for $57.1 \%$ of the total LOS cases [19-21]. Also, Piening et al. [13] and $\mathrm{Wu}$ et al. [22] have reported that the most frequently identified organism was CoNS with the frequency of $56.2 \%$ and $40 \%$, respectively. Also, Piening et al. have not reported any case of isolation of Group B Streptococcus. The reasons underlying the rise of CoNS sepsis are likely to be multifactorial, attributable in part to invasive procedures, the thin, fragile skin of neonates, and the widespread use of central venous catheters and lipid emulsions in parenteral nutrition $[20,23]$. According to the low mortality rate, CoNS infections are relatively benign infections, at least in comparison with GNR or $S$. aureus infections $[16,24]$. In consistency with our study, it has shown that a more than three-fold increased adjusted case fatality risk caused by gram-negative bacteria compared to the GPC, especially Staphylococcus species [13]. Despite being the most frequently isolated pathogen of neonatal sepsis, the significance of CoNS in neonatal morbidities may be underestimated and needs to be elucidated [25].

Although our results did not reach statistical significance, CRP and conjugated bilirubin tended to be higher and platelet levels tended to be lower in GNR sepsis. The lack of statistical significance could be due to the small sample size in this study. The results from this study further add to the evidence that early-onset cholestatic jaundice is common in GNR neonatal septicemia. Khalil et al. [26] reported that cholestatic jaundice occurred at a rate of $42.5 \%$ in GNR septicemia [26]. In a retrospective analysis of neonatal sepsis cases, $25 \%$ of the infants had some degree of cholestasis [6]. Cholestasis may be due to the pathogenic role of circulating endotoxins in causing biliary stasis and hepatic parenchymal injury [26]. 
Although all GNRs were susceptible to carbapenems, the sensitivity to ceftriaxone was $78 \%$ in the present study. Cephalosporin resistance in GNRs is an increasing problem in NICUs that makes challenging the decision of empiric antibiotic treatment [27].

LOS due to GNRs seems to display higher CRP and conjugated bilirubin values than cases that arise from GPCs. To accelerate the pace toward improved outcomes, we must first develop and validate an accepted consensus on bacteriological profiles and their antimicrobial susceptibility patterns for every NICU. Simple clues in clinical and laboratory findings may help to estimate whether the bacteria gram-positive or negative before the blood culture results. For best results in infection management, nurseries should periodically review their bacterial sensitivity patterns and antibiotic policies.

Conflict of Interest: No conflict of interest was declared by the authors.

Financial Disclosure: The authors declared that this study has received no financial support.

Authorship Contributions: Concept - AG, ST; Design - ST; Supervision - AG, ST; Materials - ST; Data collection and/or processing AG; Analysis and/or interpretation - AG, ST; Literature review - AG, ST; Writing - AG; Critical review - ST.

\section{REFERENCES}

1. Brady MT. Health care-associated infections in the neonatal intensive care unit. Am J Infect Control 2005;33:268-75. [CrossRef]

2. Aziz K, McMillan DD, Andrews W, Pendray M, Qiu Z, Karuri S, et al. Variations in rates of nosocomial infection among Canadian neonatal intensive care units may be practice-related. BMC Pediatr. 2005;5(1):1.

3. Getabelew A, Aman M, Fantaye E, Yeheyis T. Prevalence of Neonatal Sepsis and Associated Factors among Neonates in Neonatal Intensive Care Unit at Selected Governmental Hospitals in Shashemene Town, Oromia Regional State, Ethiopia, 2017. Int J Pediatr 2018;2018:7801272. [CrossRef]

4. Ferguson JK, Gill A. Risk-stratified nosocomial infection surveillance in a neonatal intensive care unit: report on 24 months of surveillance. J Paediatr Child Health 1996;32:525-31. [CrossRef]

5. Sohn AH, Garrett DO, Sinkowitz-Cochran RL, Grohskopf LA, Levine GL, Stover BH, et al; Pediatric Prevention Network. Prevalence of nosocomial infections in neonatal intensive care unit patients: Results from the first national point-prevalence survey. J Pediatr 2001;139:821-7. [CrossRef]

6. Takci S, Hanoglu D, Hascelik G, Yigit S, Korkmaz A, Yurdakok M. Neonatal cholestasis in gram-negative septicaemia. J Pediatr Gastroenterol Nutr 2012;55:e153. [CrossRef]

7. Turkish Neonatal Society; Nosocomial Infections Study Group. Nosocomial infections in neonatal units in Turkey: epidemiology, problems, unit policies and opinions of healthcare workers. Turk J Pediatr 2010;52:50-7.

8. Couto RC, Carvalho EA, Pedrosa TM, Pedroso ER, Neto MC, Biscione FM. A 10-year prospective surveillance of nosocomial infections in neonatal intensive care units. Am J Infect Control 2007;35:183-9.
9. Vergnano S, Sharland M, Kazembe P, Mwansambo C, Heath PT. Neonatal sepsis: an international perspective. Arch Dis Child Fetal Neonatal Ed 2005;90:F220-4. [CrossRef]

10. Kimberlin DW, Palazzi DL, Whitley RJ. Therapy for Perinatal and Neonatal Infections: Neonatal Sepsis. In: Rudolph CD, editor. Rudolph's Pediatrics. 22 ${ }^{\text {nd }}$ ed. New York: 2011; p. 902-12.

11. Zafar N, Wallace CM, Kieffer P, Schroeder P, Schootman M, Hamvas $A$. Improving survival of vulnerable infants increases neonatal intensive care unit nosocomial infection rate. Arch Pediatr Adolesc Med 2001;155:1098-104. [CrossRef]

12. Raymond J, Aujard Y. Nosocomial infections in pediatric patients: a European, multicenter prospective study. European Study Group. Infect Control Hosp Epidemiol 2000;21:260-3. [CrossRef]

13. Piening BC, Geffers C, Gastmeier P, Schwab F. Pathogen-specific mortality in very low birth weight infants with primary bloodstream infection. PLoS One 2017;12:e0180134. [CrossRef]

14. Tallur SS, Kasturi AV, Nadgir SD, Krishna BV. Clinico-bacteriological study of neonatal septicemia in Hubli. Indian J Pediatr 2000;67:169-74.

15. Mutlu M, Aslan Y, Saygin B, Yilmaz G, Bayramoğlu G, Köksal I. Neonatal Sepsis Caused by Gram-negative Bacteria in a Neonatal Intensive Care Unit: A Six Years Analysis. HK J Paediatr (new series) 2011;16:253-7.

16. Karlowicz MG, Buescher ES, Surka AE. Fulminant late-onset sepsis in a neonatal intensive care unit, 1988-1997, and the impact of avoiding empiric vancomycin therapy. Pediatrics 2000;106:1387-90. [CrossRef]

17. Srivastava S, Shetty N. Healthcare-associated infections in neonatal units: lessons from contrasting worlds. J Hosp Infect 2007;65:292-306.

18. Yunanto A, Margareta Y, Indah D, Pratiwi N. Bacteriological pattern and antibiotic susceptibility in neonatology ward Ulin General Hospital, Banjarmasin, Indonesia. Oral Surg Oral Med Oral Pathol. 2014;1:10-3.

19. Bizzarro MJ, Raskind C, Baltimore RS, Gallagher PG. Seventy-five years of neonatal sepsis at Yale: 1928-2003. Pediatrics 2005;116:595602. [CrossRef]

20. Isaacs D; Australasian Study Group For Neonatal Infections. A ten year, multicentre study of coagulase negative staphylococcal infections in Australasian neonatal units. Arch Dis Child Fetal Neonatal Ed 2003;88:F89-93. [CrossRef]

21. Stoll BJ, Hansen N, Fanaroff AA, Wright LL, Carlo WA, Ehrenkranz RA, et al. Late-onset sepsis in very low birth weight neonates: the experience of the NICHD Neonatal Research Network. Pediatrics 2002;110:285-91. [CrossRef]

22. Wu JH, Chen CY, Tsao PN, Hsieh WS, Chou HC. Neonatal sepsis: a 6-year analysis in a neonatal care unit in Taiwan. Pediatr Neonatol 2009;50:88-95. [CrossRef]

23. Freeman J, Goldmann DA, Smith NE, Sidebottom DG, Epstein MF, Platt R. Association of intravenous lipid emulsion and coagulase-negative staphylococcal bacteremia in neonatal intensive care units. N Engl J Med 1990;323:301-8. [CrossRef]

24. Stoll BJ, Gordon T, Korones SB, et al. Late-onset sepsis in very low birth weight neonates: a report from the National Institute of Child Health and Human Development Neonatal Research Network. J Pediatr 1996;129:63-71. [CrossRef]

25. Dong Y, Speer CP, Glaser K. Beyond sepsis: Staphylococcus epidermidis is an underestimated but significant contributor to neonatal morbidity. Virulence 2018;9:621-33. [CrossRef]

26. Khalil S, Shah D, Faridi MM, Kumar A, Mishra K. Prevalence and outcome of hepatobiliary dysfunction in neonatal septicaemia.J Pediatr Gastroenterol Nutr 2012;54:218-22. [CrossRef]

27. Tsai MH, Chu SM, Hsu JF, Lien R, Huang HR, Chiang MC, et al. Risk factors and outcomes for multidrug-resistant Gram-negative bacteremia in the NICU. Pediatrics 2014;133:e322-9. [CrossRef] 